\title{
Diagnosis, genetic variations, virulence, and toxicity of AHPND-positive Vibrio parahaemolyticus in Penaeus monodon
}

\author{
Md. Mer Mosharraf Hossain, et al. [full author details at the end of the article]
}

Received: 25 May 2020 / Accepted: 18 September 2020 / Published online: 28 September 2020

(C) Springer Nature Switzerland AG 2020

\begin{abstract}
Acute hepatopancreatic necrosis disease (AHPND) is an emerging shrimp (Penaeus monodon) disease caused by Vibrio parahaemolyticus (VP) since 2013 in Bangladesh. The aim of this work was to evaluate a PCR and RT-PCR techniques as rapid methods for detecting $V$. parahaemolyticus AHPND-positive $P$. monodon using genetic markers. Healthy and diseased shrimp ( $P$. monodon) samples were collected from three monitoring stations. The samples were enriched in TCBS plates and DNA extraction from the cultured bacteria. DNA quantifications, PCR amplification, RT-PCR, and gene sequencing were done for the detection of $V$. parahaemolyticus AHPND-positive $P$. monodon. The sequence of PCR amplicons showed $100 \%$ identity and significant alignment with $V$. parahaemolyticus. The primers used provided high specificity for $V$. parahaemolyticus in PCR detection compared with another Vibrio species. In the PCR, amplification resulted positive amplicons, whereas, non-AHPND isolates showed no amplicons. Neighbor-joining methods indicated that all genes evolved from a common ancestor and clades have different traits with very low genetic distance and low variability. The pairwise alignment scores of atpA, tox, blaCARB, 16S rRNA, and pirA genes were 100.0, 98.90, 98.89, 95.53, and 41.42, respectively. The RT-qPCR exposed variable expression levels for all genes in the AHPND-positive strain. Homology analysis and distance matrix exhibited all genes to have the lowest similarity and most divergence, offering the highest specificity. In this study, the expression and variability of target genes confirmed the presence of $V$. parahaemolyticus in all sampling sites. The results suggested that PCR amplification, RT-qPCR, and gene sequencing can be used for the rapid detection of $V$. parahaemolyticus in AHPND-positive $P$. monodon that may lead to subsequent prevention and treatment research in the future for managing this disease.
\end{abstract}

Keywords Diagnosis $\cdot$ Penaeus monodon - Vibrio parahaemolyticus $\cdot$ Acute hepatopancreatic necrosis disease (AHPND genetic variations, virulence, and toxic gene)

\section{Introduction}

Vibriosis is one of the major disease problems in shellfish and finfish aquaculture responsible for the mortality of cultured shrimp worldwide (Mohney et al. 1994). Opportunistic pathogens 
with highly virulent strains (Ishimaru et al. 2009) include Vibrio alginolyticus, Vibrio anguillarum, Vibrio harveyi and Vibrio parahaemolyticus (Kannapiran et al. 2009). In an initial outbreak in the southwest of China in 2009, acute hepatopancreatic necrosis disease (AHPND) had its rapid, lethal effect in early stages of shrimp and had spread all over the world. Over the past 40 years, Asia's farmed shrimp aquaculture industry is impacted by episodes of disease, notably AHPND, resulting in substantial national income losses (Shinn et al. 2018a). $V$. parahaemolyticus is widely distributed in marine environments and frequently isolated from a variety of raw seafood, particularly shellfish. The V. parahaemolyticus harboring virulence genes such as $t d h$ and trh (Zhang and Orth 2013) have toxic effect on human health.

AHPND is characterized by high mortality generally when shrimp is 1 month old or post larvae is around 20-30 days old (De Schryver et al. 2014); it is responsible for a significant proportion of economic losses recorded from at least eight Asian territories. An empty gut and an atrophied, pale hepatopancreas (Lai et al. 2015), massive sloughing off of the epithelial cells of the hepatopancreas (Sirikharin et al. 2015), and hemocyte infiltration are caused by a specific set of $V$. parahaemolyticus (De Schryver et al. 2014).

AHPND was first detected in shrimp farms in southwestern Bangladesh in 2013 and consequently spread to other cultural areas of Bangladesh. The pathogen is transferred orally and then localizes at the shrimp gastrointestinal tract and creates a poison that causes tissue devastation and invalidism of the shrimp digestive system known as the hepatopancreas (Zorriehzahra and Banaederakhshan 2013). To control AHPND, farmers implemented prevention through pond eradication and renovation, but it could not stop outbreaks of the pathogen once the disease appeared repeatedly in shrimp farms. To prevent AHPND, its causative agent (Praveena et al. 2014) namely V. parahaemolyticus must be characterized thoroughly. Although plasmid-encoded binary toxins pirA and pirB (Kim et al. 2015) are found to be the primary causes of AHPND, whether other virulent factors are tox $\mathrm{R}$ and toxA genes (Kim et al. 1999; Sirikharin et al. 2015) commonly present in V. parahaemolyticus and may play essential roles in genetic diversity analyzed by 16S rRNA gene (Feng et al. 2017) during shrimp infection remains unknown (Li et al. 2017).

The PCR primers target specific DNA sequences using PCR present in samples in several locations, this tool identified pathogenic V. parahaemolyticus causing AHPND (Han et al. 2015a). The primer set AP1 and AP2 which target the DNA sequences of AHPND was the first PCR diagnostic tool used in 2013 (Flegel and Lo 2014a). Three sets of AHPND primers (AP1, AP2, and AP3), AP2 showed a false positive result due to the plasmid mutation lacking the toxin gene (Flegel and Lo 2014b). Among (AP1, AP2, and AP3) the primer sets, AP3 demonstrated the highest sensitivity and best specificity (Flegel 2014). The TUMSAT-Vp3 primer used targeting the AHPND DNA sequences (Tinwongger et al. 2014). The AP4 nested PCR method showed higher sensitivity and amplified pirA and pirB genes in V. parahaemolyticus and detected AHPND isolates containing these two genes (Dangtip et al. 2015). Among the recent PCR methods, AP3 method is considered the most promising tool for detecting AHPND which targets the pirA as it exhibited high sensitivity and specificity (Soto-Rodriguez et al. 2015). Thus, the use of AP3 primers which can detect pirA gene and duplex PCR method to detect pirA and pirB genes is the most recommended confirmatory tests for AHPND detection (Han et al. 2015b). The current disease problems in Asia, notably AHPND caused by pathogenic isolates of Vibrio parahaemolyticus (Shinn et al. 2018b). In 2020, Santos et al. (2020) reported the different strategies in diagnosing and potential treatments for AHPND and the discovery of pathogenic mechanisms involved in AHPND. 
This study aimed to analyze the specific detection, genetic variability, and expression of virulence and toxic genes using rapid detection method in $V$. parahaemolyticus isolated from Penaeus monodon in affected areas in Bangladesh remain unclear, which may include the essential groundwork for advance research of AHPND.

\section{Materials and methods}

\section{Isolation and storage of Vibrio parahaemolyticus isolates}

AHPND-causative Vibrio parahaemolyticus was isolated from shrimp culture ponds or ghers in PCF Feed Industries Ltd. in Bagherhat, C.P. Bangladesh Co., Ltd. in Khulna, and Radiant Shrimp Farms Ltd. in Sathkhira respectively. Dead and moribund juvenile $(\sim 2 \mathrm{~g})$ shrimps (Penaeus monodon) were collected from 30 AHPND outbreaks ponds or ghers. About $25 \mathrm{~g}$ of each type of sample (gills, guts, and hepatopancreas) was thoroughly triturated in a sterile mortar and pestle with use of $225 \mathrm{ml}$ of alkaline saline peptone water (ISO) (Thermo Scientific $^{\mathrm{TM}}$ ) and homogenized for $2 \mathrm{~min}$ in a stomacher (Life Technologies, CA, USA) (Chonsin et al. 2015). Tenfold serial dilution of $1 \mathrm{ml}$ of homogenates was established in alkaline saline peptone water $\left(\mathrm{ASPW}^{+}\right)$with three replicates which were generated and shaken at $170 \mathrm{rpm}$ at $37{ }^{\circ} \mathrm{C}$ for $18 \mathrm{~h}$. A total of $100 \mu \mathrm{l}$ volumes of the extract was plated onto thiosulfate-citrate-bile salts-sucrose (TCBS) plates (Remel Inc., Santa Fe Drive, Lenexa, USA) for $24 \mathrm{~h}$. The Vibrio parahaemolyticus sucrose agar (VPSA) incubated at $37^{\circ} \mathrm{C}$ for $24 \mathrm{~h}$. The characteristic large colonies (3-4 mm) with light blue or green centers on TCBS and VPSA were regarded as presumptive $V$. parahaemolyticus and further subjected to morphological, cultural, and biochemical characterization. A series of biochemical tests as per BAM, USFDA method (Kaysner and DePaola 2004) was used for the identification of Vibrio isolates.

All colonies were picked and streaked on tryptone soya agar (TSA) (Sigma-Aldrich, Germany) supplemented with 3\% (w/v) NaCl (Sigma-Aldrich, Germany). After 24 h incubation, one colony from each plate was inoculated into tryptone soya broth (TSB) (Sigma-Aldrich, Germany) enriched with $3 \%(w / v) ~ \mathrm{NaCl}$ grown by shaking at $170 \mathrm{rpm}$ at $37{ }^{\circ} \mathrm{C}$ for $12 \mathrm{~h}$. The bacterial suspension was incubated at $37^{\circ} \mathrm{C}$ for $12 \mathrm{~h}$ with continuous shaking. The total $12 \mathrm{~h}$ culture volume $(50 \mathrm{ml})$ was used as inoculum for $500 \mathrm{ml}$ fresh medium $(500 \mathrm{ml})$ followed by continued cultivation with shaking until the OD600 reached 0.6 (approximately 6-8 h) and was equivalent to approximately $2 \times 10^{8}$ cells per $\mathrm{ml}$. The bacterial cells were removed by centrifugation at $8500 \mathrm{rpm}$ for $10 \mathrm{~min}$ at $4{ }^{\circ} \mathrm{C}$; the supernatant was used to prepare crude protein fractions. Subsequently, $1 \mathrm{ml}$ of medium was mixed with $1 \mathrm{ml}$ of $50 \%(\mathrm{v} / \mathrm{v})$ ultrapure glycerol (Invitrogen ${ }^{\mathrm{TM}}$ ) and stored at $-80{ }^{\circ} \mathrm{C}$. A total of $1 \mathrm{ml}$ bacterial cells of overnight culture was centrifuged, and the pellet was suspended in $400 \mu \mathrm{l}$ of $\mathrm{ddH} 2 \mathrm{O}$. The bacterial suspension was centrifuged at 11,000 rpm for $6 \mathrm{~min}$. The supernatant was used as DNA template for PCR assay.

\section{Bacterial genomic and plasmid DNA extraction}

A general DNA extraction technique was applied to obtain the DNA of 30 isolates from healthy/suspected/infected shrimp stomach or hepatopancreatic tissue. Bacterial genomic DNA and plasmid DNA were applied with DNAzol ${ }^{\mathrm{TM}}$ reagent to isolate genomic DNA (a vast spectrum, fast isolation, and large recovery of genomic DNA kits, Invitrogen ${ }^{\mathrm{TM}}$, and PureLinkR Pro Quick96 Plasmid Kit, Invitrogen ${ }^{\mathrm{TM}}$ ), following the manufacturer's instruction. 
In this study, $0.01-1 \mathrm{ng}$ of DNA extracted from bacterial isolate or 10-100 ng from shrimp tissue produces the volume of template DNA in the $25 \mu \mathrm{l}$ PCR reaction.

\section{Primers used for PCR amplification}

The well-conserved regulatory genes tox $\mathrm{R}$ and toxA (Sirikharin et al. 2015), a highly conserved 16S rRNA gene (Tarr et al. 2007), a novel species-specific genetic marker blaCARB17 (Li et al. 2016), AP1 and AP2 (Feng et al. 2017) and pirA gene (AP3) (Sirikharin et al. 2014), was analyzed and examined for PCR amplification to produce the expression of virulence and toxic genes $t h$, $t d h$, and trh of AHPND $V$. parahaemolyticus isolates (Gutierrez West et al. 2013). The sequence of primers applied for the amplification of target genes is listed in Table 1.

Table 1 The sequence of primer pairs (forward and reverse) for PCR amplification of $t r h, t d h, 16 \mathrm{~S}$ rRNA, toxR, atp $\mathrm{A}$, th , pirA, tox $\mathrm{A}$, pir $\mathrm{B}$, and blaCARB-17 targeting genes

\begin{tabular}{|c|c|c|c|c|}
\hline Primer pair & Oligonucleotide sequence $\left(5^{\prime}-3^{\prime}\right)$ & $\begin{array}{l}\text { Product } \\
\text { length }\end{array}$ & Target gene & Reference \\
\hline $\begin{array}{l}\text { Trh-F } \\
\text { Trh-R }\end{array}$ & $\begin{array}{l}\text { CTCTACTTTGCTTTCAGT } \\
\text { AATATTCTGGAGTTTCAT }\end{array}$ & $460 \mathrm{bp}$ & trh & $\begin{array}{l}\text { (Suthienkul et al. } \\
\text { 1995) }\end{array}$ \\
\hline $\begin{array}{l}\text { Tdh-F } \\
\text { Tdh-R }\end{array}$ & $\begin{array}{l}\text { CGTTGATTATTCTTTTACGA } \\
\text { TTTGTTGGATATACACAT }\end{array}$ & $623 \mathrm{bp}$ & $t d h$ & $\begin{array}{l}\text { (Karunasagar et al. } \\
\text { 1996) }\end{array}$ \\
\hline $\begin{array}{l}V .16 \mathrm{~S}-700 \mathrm{~F} \\
V .16 \mathrm{~S}-1325 \mathrm{R}\end{array}$ & $\begin{array}{l}\text { CGGTGAAATGCGTAGAGA T } \\
\text { TTACTAGCGATTCCGAGTTC }\end{array}$ & $663 \mathrm{bp}$ & 16S rRNA & (Tarr et al. 2007) \\
\hline $\begin{array}{l}\text { ToxB-F } \\
\text { ToxB-R }\end{array}$ & $\begin{array}{l}\text { TGTACTGTTGAACGCCTA } \\
\text { CACGTTCTCATACGAGTG }\end{array}$ & 503 bp & tox $\mathrm{R}$ & (Neogi et al. 2010) \\
\hline $\begin{array}{l}\operatorname{atpA-VP-F} \\
\operatorname{atpA-VP-R}\end{array}$ & $\begin{array}{l}\text { TACTAGGCCGCGTAGTA } \\
\text { CGCTGGACGTACACCT }\end{array}$ & 794 bp & atp A & (Izumiya et al. 2011) \\
\hline $\begin{array}{l}\text { AP1-F } \\
\text { AP1-R }\end{array}$ & $\begin{array}{l}\text { CCTTGGGTGTGCTTAGAGGATG } \\
\text { GCAAACTATCGCGCAGAACACC }\end{array}$ & $700 \mathrm{bp}$ & & (Flegel and Lo 2013) \\
\hline $\begin{array}{l}\text { AP2-F } \\
\text { AP2-R }\end{array}$ & $\begin{array}{l}\text { TCACCCGAATGCTCGCTTGTGG } \\
\text { CGTCGCTACTGTCTAGCTGAAG }\end{array}$ & $700 \mathrm{bp}$ & & (Flegel and Lo 2013) \\
\hline $\begin{array}{l}\text { TLH-F } \\
\text { TLH-R }\end{array}$ & $\begin{array}{l}\text { AAAGCGGATTATGCAGAAGCACTG } \\
\text { GCTACTTTCTAGCATTTTCTCTGC }\end{array}$ & $450 \mathrm{bp}$ & $t l h$ & $\begin{array}{l}\text { (Dickinson et al. } \\
\text { 2013) }\end{array}$ \\
\hline $\begin{array}{l}\text { AP3-F } \\
\text { AP3-R }\end{array}$ & $\begin{array}{l}\text { ATGAGTAACAATATAAAACA } \\
\text { TGAAAC } \\
\text { GTGGTAATAGATTGTACAGAA }\end{array}$ & $333 \mathrm{bp}$ & pirA & $\begin{array}{l}\text { (Sirikharin et al. } \\
\text { 2014) }\end{array}$ \\
\hline $\begin{array}{l}\text { Tt16AP4-F1* } \\
\text { AP4-R1 }\end{array}$ & $\begin{array}{l}\text { ATGAGTAACAATATAAAACA } \\
\text { TGAAAC } \\
\text { ACGATTTCGACGTTCCCCAA }\end{array}$ & $1269 \mathrm{bp}$ & tox $\mathrm{A}$ & (Dangtip et al. 2015) \\
\hline $\begin{array}{l}\text { AP4-F2 } \\
\text { AP4-R2 }\end{array}$ & $\begin{array}{l}\text { TTGAGAATACGGGACGTGGG } \\
\text { GTTAGTCATGTGAGCACCTTC }\end{array}$ & $230 \mathrm{bp}$ & toxA & (Dangtip et al. 2015) \\
\hline $\begin{array}{l}\text { PIR-F1 } \\
\text { AP4-R1 }\end{array}$ & $\begin{array}{l}\text { TGACTATTCACGATTGGACTG } \\
\text { CACGACTAGCCATTGTTA }\end{array}$ & 284 bp & pirA & (Han et al. 2015b) \\
\hline $\begin{array}{l}\text { PIR-F2 } \\
\text { PIR-R2 }\end{array}$ & $\begin{array}{l}\text { TGATGAAGTGATGGGTGCTC } \\
\text { TGTAAGCGCCGTTTAACTCA }\end{array}$ & 392 bp & pir $\mathrm{B}$ & (Han et al. 2015b) \\
\hline $\begin{array}{l}\text { qPCR-F } \\
\text { qPCR-R }\end{array}$ & $\begin{array}{l}\text { TTGGACTGTCGAACCAAACG } \\
\text { GCACCCCATTGGTATTGAATG } \\
\text { Probe: } \\
\text { AGACAGCAAACATACACCTA } \\
\quad \text { TCATCCCGCA }\end{array}$ & $135 \mathrm{bp}$ & pirA & (Han et al. 2015b) \\
\hline $\begin{array}{l}\text { CARB-F } \\
\text { CARB-R }\end{array}$ & $\begin{array}{l}\text { ACC(T)TTGATGGAAGATA } \\
\text { T(C)TAACTTTCTTTGTAGTGC(A) }\end{array}$ & 303 bp & blaCARB -17 & (Li et al. 2016) \\
\hline
\end{tabular}

*Note that primer AP4-F1 is identical to primer AP3-F from the AP3 method 


\section{PCR amplification of target genes}

The template DNA derived from AHPND-suspected or positive 30 isolates was used for PCR amplification (Sirikharin et al. 2014) with specific primer set for particular target genes in Table 1. The final reaction volume was $10 \mu$ l, containing $5 \mu \mathrm{l}$ of Green Master Mix (GoTagG2), $1 \mu \mathrm{l}$ of $10 \mu \mathrm{M}$ primers, $1 \mu \mathrm{l}$ of template DNA, and $3 \mu \mathrm{l}$ nuclease-free water. The thermal profile for DNA amplification in a thermal cycler (Professional standard gradient, Biometra, Germany) was as follows: preheating at $95{ }^{\circ} \mathrm{C}$ for 2 min and 1 min denaturation at $94{ }^{\circ} \mathrm{C}$ for 35 cycles. The annealing temperature was $58^{\circ} \mathrm{C}$ (primer-specific) for $1 \mathrm{~min}$ and then was elongated or extended to $72{ }^{\circ} \mathrm{C}$ for $1 \mathrm{~min}$ to a final extension of $72{ }^{\circ} \mathrm{C}$ for $5 \mathrm{~min}$. Moreover, $1 \%$ agarose gel was used to separate the amplified PCR product from each sample electrophoretically (Nacalai Tesque, Inc., Kyoto, Japan) at a constant voltage of 120 for $30 \mathrm{~min}$ in the $1 \times$ TAE buffer. The gel was stained with $10 \mu$ ethidium bromide $(10 \mathrm{mg} / \mathrm{mL}$ in $100 \mathrm{~mL}$ of DW) for 10 min and visualized under ultraviolet (UV) light, and molecular weight marker was $1 \mathrm{~Kb}$ plus DNA ladder (Invitrogen ${ }^{\mathrm{TM}}$, Thermo Fisher Scientific). The DNA bands were observed on high-performance UV transilluminator and photographed with a gel documentation system (BioDoc-It ${ }^{\mathrm{TM}}$ Imaging system, Cambridge, UK). The sequences (next-generation sequencing platform, 1st Base Laboratories, Malaysia) of the PCR amplicons were analyzed by MEGA X (version 10.0.5) (Kumar et al. 2018), DNAMAN (Lynnon Biosoft Corporation, USA, version 10.0.2.100) (Austin 2010) and Geneious prime software (Biomatters Limited, New Zealand, version 2020.0.2). The NCBI-BLAST (GeneBank) and SMART BLAST were used for sequence analysis (Table 2) and the specificity is shown in Table 3. The multiple sequence alignments were monitored using Geneious prime, ClustalW, and DNAMAN software. The neighbor-joining method (Saitou and Nei 1987) and the maximum composite likelihood method (Tamura et al. 2004) were used to determine the evolutionary history and distance analyzed by MEGA X.

\section{Quantitative PCR for CDNA synthesis}

The RNA was extracted using the Ambion RNAqueous Midi Kit (InvitrogenTM) from TSB+ (Sigma-Aldrich, Germany) culture medium via centrifugation at $8000 \mathrm{~g}$ for $10 \mathrm{~min}$ in accordance with the instruction. Thermo Scientific ${ }^{\mathrm{TM}}$ Culti-Loops ${ }^{\mathrm{TM}}$ V. parahaemolyticus ATCC ${ }^{\mathrm{TM}}$ $17802^{\mathrm{TM}}$ was used as a negative control. Thermo Scientific Maxima H Minus cDNA Synthesis Master Mix with dsDNase provides a simple workflow that combines genomic DNA elimination and cDNA synthesis in a one-tube procedure. The cDNA reaction components are premixed into a complete master mix that is convenient to use, reduces pipeting steps, and is optimized for cDNA synthesis in two-step quantitative RT-PCR (RT-qPCR) applications.

\section{Homology tree of target genes within AHPND-positive isolates}

The DNAMAN software (Lynnon Biosoft Corporation, USA, version 10.0.2.100) was used to analyze the homology of target genes within AHPND-positive isolates by applying an effective alignment method. The NCBI nucleotide collection (nr) and whole-genome shotgun (wgs) database (accession nos.: AP014860.1, LK021128.1, CP021148.1, and CP033146.1) were used to retrieve target genes toxR, 16S rRNA, AP1, AP2, pirA (AP3), toxA, blaCARB$17, t l h, a t p \mathrm{~A}, t d h$, and $t r h$-like sequences. The sequence of the target genes was used to construct the homology trees. 
Table 2 The amplification of PCR result of AP1, AP2, toxR, 16S rRNA, pirA (AP3), toxA, blaCARB-17, tlh, $a t p \mathrm{~A}, t d h$, and trh in AHPND-positive isolates

\begin{tabular}{|c|c|c|c|c|c|c|c|c|c|c|c|c|}
\hline \multirow{2}{*}{$\begin{array}{l}\text { Bacterial } \\
\text { isolates }\end{array}$} & \multicolumn{11}{|c|}{ Primer pair/target gene } & \multirow{2}{*}{$\begin{array}{l}\text { Identity* } \\
(\%)\end{array}$} \\
\hline & tox $\mathrm{R}$ & $\begin{array}{l}16 \mathrm{~S} \\
\text { rRNA }\end{array}$ & AP1 & AP2 & AP3 & toxA & $\begin{array}{l}\text { blaCARB } \\
-17\end{array}$ & tlh & $\operatorname{atp} \mathrm{A}$ & $t d h$ & trh & \\
\hline ahpn-1 & + & + & - & + & + & - & + & + & + & - & - & 100 \\
\hline ahpn-3 & + & + & + & + & + & + & + & + & + & + & + & 100 \\
\hline ahpn-8 & + & + & + & + & + & + & + & + & + & + & + & 100 \\
\hline ahpn-11 & + & + & + & + & + & + & + & + & + & - & - & 100 \\
\hline ahpn-12 & + & + & + & - & + & + & + & + & + & - & - & 100 \\
\hline ahpn-13 & + & + & + & + & + & + & + & + & - & + & + & 99 \\
\hline ahpn-14 & + & + & + & + & + & + & + & + & + & + & - & 99 \\
\hline ahpn-15 & + & + & + & + & + & + & + & + & + & + & + & 100 \\
\hline ahpn-16 & + & + & + & + & + & - & + & + & + & + & + & 99 \\
\hline ahpn-17 & + & + & + & + & + & + & + & + & + & + & + & 99 \\
\hline ahpn-18 & + & + & - & + & + & + & + & + & + & + & - & 99 \\
\hline ahpn-19 & + & + & + & + & + & - & + & + & + & - & - & 99 \\
\hline ahpn-20 & + & + & + & + & + & + & + & + & + & + & + & 100 \\
\hline ahpn-21 & + & + & + & + & + & - & + & + & + & - & - & 99 \\
\hline ahpn-22 & + & + & + & + & + & + & + & + & + & - & - & 99 \\
\hline ahpn-23 & + & + & + & + & + & + & + & + & - & + & + & 99 \\
\hline ahpn-24 & + & + & - & + & + & + & + & + & + & + & + & 99 \\
\hline ahpn-25 & + & + & + & + & + & + & + & + & + & + & + & 100 \\
\hline ahpn-26 & + & + & + & + & + & + & + & + & + & - & + & 100 \\
\hline ahpn-27 & + & + & + & - & + & - & + & + & - & - & - & 99 \\
\hline ahpn-28 & + & + & + & - & + & - & + & + & - & - & - & 99 \\
\hline ahpn-29 & + & + & + & + & + & + & + & + & - & + & + & 100 \\
\hline ahpn-30 & + & + & + & + & + & + & + & + & + & + & + & 100 \\
\hline
\end{tabular}

* Summary of metadata for genome sequence using BLAST (nr) in NCBI producing species identity of 30 isolates collected from major shrimp farming regions of Bangladesh

\section{Expression analysis of target genes by qPCR}

The primer pair (qPCR-forward and qPCR-reverse, and probe) in Table 1 was chosen to quantify pirA gene expression. ATCC17802 was used as the negative control and 16S rRNA gene were selected for the normalization of gene expression in RT-qPCR. Every $1 \mu$ of cDNA was used as template. The final reaction volume of $20 \mu \mathrm{l}$ consisted of $10 \mu \mathrm{l}$ of Syber Green Master Mix (Thermo Fisher Scientific), $1.6 \mu \mathrm{l}$ of $10 \mathrm{mM}$ forward and reverse primer, $0.4 \mu \mathrm{l}$ of ROX Reference Dye (Invitrogen ${ }^{\mathrm{TM}}$ ), $2 \mu$ of cDNA template, and $6 \mu$ of ddH2O for RT-qPCR (7500 Fast Real-time PCR system, Applied Biosystems). The thermal profile was as follows: $95^{\circ} \mathrm{C}$ for $30 \mathrm{~s}$, followed by 40 cycles of $95{ }^{\circ} \mathrm{C}$ for $5 \mathrm{~s}$ and $60{ }^{\circ} \mathrm{C}$ for $15 \mathrm{~s}$. Each reaction was carried out in triplicate and analyzed by ABI 7500 v2.0.6. software.

\section{Results}

Among the 30 AHPND outbreak shrimp ponds or ghers yielded a total of 30 isolates that were stored at $-80{ }^{\circ} \mathrm{C}$. The sequence of PCR amplicon analysis of the 30 isolates yielded 23 $V$. parahaemolyticus positive samples that produced $100 \%$ identity and significant alignment with $V$. parahaemolyticus. The other 7 isolates corresponded to common marine 
microorganisms that produced $99 \%$ significant alignment with Photobacterium and $V$. harveyi (Table 2). In the initial screening, 23 isolates provided a positive signal with toxR, 16S rRNA, pirA, blaCARB-17, and $t$. . The primers confirmed that six isolates isolated from shrimp in growing ponds (ahpn-3, ahpn-8, ahpn-15, ahpn-20, ahpn-25, and ahpn-30) contained toxR, 16S rRNA, AP1, AP2, pirA (AP3), toxA, blaCARB-17, tlh, atpA, tlh, and trh genes, but not in the other 17 isolates (Table 2). The PCR technique determined the specificity of target genes compared with separate bacterial isolates in Table $3 ; 100 \%$ specificity was provided in V. parahaemolyticus with toxR, toxA, 16S rRNA, pirA, blaCARB-17, and th. The atpA, $t d h$, and trh genes yielded $83 \%, 77 \%$, and $85 \%$ specificities in $V$. parahaemolyticus, respectively, whereas the 30 strains were isolated from shrimp in growing ponds. V. alginolyticus isolated from shrimp yielded $66 \%$ and $33 \%$ specificities with 16S rRNA and pirA genes, respectively. The other Vibrio spp. isolated from food and ATCC sources, Pseudomonas and Enterobacter isolated from clinical sources and Aeromonas, Escherichia coli, Salmonella, and Staphylococcus isolated from food sources showed $0 \%$ specificity with tox $\mathrm{R}$, toxA, 16S rRNA, pirA (AP3), blaCARB-17, tlh, atpA, tdh, and trh (Table 3).

Agarose gel (1\%) was used to reveal the PCR amplification of target genes toxR, 16S rRNA, AP1, AP2, pirA (AP3), toxA, blaCARB-17, tlh, atpA, tdh, and trh by using AHPNDpositive representative strain ahpn-25 (the samples of ahpn-3, ahpn-8, ahpn-15, ahpn-20, ahpn25 , and ahpn-30 showed $100 \%$ identity in Table 2 and revealed all target genes by PCR in Table 2; among them, ahpn-25 was used as a representative strain) to identify $V$. parahaemolyticus in Fig. 1. Lanes 3-13 show the bands of positive amplicons at 350, 663, 700, 700, 336, 333, 303, 450, 794, 623, and $460 \mathrm{bp}$, whereas non-AHPND (ahpn-2) exhibited no amplicons in lane 2.

Table 3 The PCR methods were resulting in the specificity targeting different genes in AHPND-positive and AHPND-negative isolates

\begin{tabular}{|c|c|c|c|c|c|c|c|c|c|c|c|}
\hline \multirow[t]{2}{*}{ Species } & \multirow[t]{2}{*}{ Source } & \multirow{2}{*}{$\begin{array}{l}\text { No. of } \\
\text { isolates }\end{array}$} & \multicolumn{9}{|c|}{ Positive rate $(\%)$} \\
\hline & & & tox $\mathrm{R}$ & $\operatorname{tox} \mathrm{A}$ & $\begin{array}{l}16 \mathrm{~S} \\
\text { rRNA }\end{array}$ & pirA & $\begin{array}{l}\text { blaCARB } \\
-17\end{array}$ & tlh & $a t p \mathrm{~A}$ & $t d h$ & trh \\
\hline $\begin{array}{l}\text { Vibrio } \\
\quad \text { parahaemolyticus }\end{array}$ & Shrimp & 30 & 100 & 100 & 100 & 100 & 100 & 100 & 83 & 77 & 85 \\
\hline V. harveyi & Shrimp & 1 & 0 & 0 & 0 & 0 & 0 & 0 & 0 & 0 & 0 \\
\hline V. campbellii & Shrimp & 1 & 0 & 0 & 0 & 0 & 0 & 0 & 0 & 0 & 0 \\
\hline$V$. anguillarum & Shrimp & 3 & 0 & 0 & 66 & 33 & 0 & 0 & 0 & 0 & 0 \\
\hline V. vunificus & Food & 1 & 0 & 0 & 0 & 0 & 0 & 0 & 0 & 0 & 0 \\
\hline V. cholerae & Food & 5 & 0 & 0 & 0 & 80 & 0 & 0 & 0 & 0 & 0 \\
\hline V. metschnikovii & Food & 1 & 0 & 0 & 0 & 0 & 0 & 0 & 0 & 0 & 0 \\
\hline V. fluvialis & $\begin{array}{c}\text { ATCC } \\
*\end{array}$ & 1 & 0 & 0 & 0 & 0 & 0 & 0 & 0 & 0 & 0 \\
\hline V. mimicus & ATCC & 1 & 0 & 0 & 0 & 0 & 0 & 0 & 0 & 0 & 0 \\
\hline V. natriegens & Food & 1 & 0 & 0 & 0 & 0 & 0 & 0 & 0 & 0 & 0 \\
\hline Pseudomonas sp. & Clinical & 1 & 0 & 0 & 0 & 0 & 0 & 0 & 0 & 0 & 0 \\
\hline Aeromonas sp. & Food & 1 & 0 & 0 & 0 & 0 & 0 & 0 & 0 & 0 & 0 \\
\hline Escherichia coli & Food & 2 & 0 & 0 & 0 & 0 & 0 & 0 & 0 & 0 & 0 \\
\hline Salmonella sp. & Food & 2 & 0 & 0 & 0 & 0 & 0 & 0 & 0 & 0 & 0 \\
\hline Staphylococcus sp. & Food & 2 & 0 & 0 & 0 & 0 & 0 & 0 & 0 & 0 & 0 \\
\hline Enterobacter sp. & Clinical & 1 & 0 & 0 & 0 & 0 & 0 & 0 & 0 & 0 & 0 \\
\hline
\end{tabular}

*The American Type Culture Collection 
The amplified PCR products of the target genes with six AHPND-positive representative isolates (ahpn-3, 8, 15, 20, 25, and 30) received 99\% identity (NCBI, BLAST) with their closed sequence in Table 2 and Fig. 2a and exhibited high homology. To construct the phylogenetic relationship (Li et al. 2016), 8 Vibrio spp. were selected from GeneBank to compare with target gene sequences; all genes were derived from a common ancestor (Fig. 2a). All genes showed a common ancestor (accession no. CP022245.1), whereas all clades were derived with different traits with very low genetic distance (Fig. 2b). The sequences of the PCR amplification of target genes (toxR, 16S rRNA, pirA (AP3), toxA, blaCARB-17, th, $a t p \mathrm{~A}, t d h$, and $t r h$ ) from an AHPND-positive representative strain (ahpn-25) were aligned with the reference strain of $V$. parahaemolyticus (accession no. CP034571.1) with low variability (Fig. 3).

The PCR amplification, agarose gel electrophoresis, and RT-qPCR assay of target genes 16S rRNA, blaCARB-17 and atpA revealed accurate amplified fragment in Fig. 1 and comparatively high expression and constantly maintained 100\% specificity in Table 2 for V. parahaemolyticus (Izumiya et al. 2011; Dickinson et al. 2013) in parallel with different isolates in Table 3. The unique homology was found for target genes (16S rRNA, tox, blaCARB-17, pirA, atpA, tlh, $t d h$, and $t r h$ ) compared with another Vibrio spp. The degrees of similarity ranges were (23-58\%) for pirA, trh, blaCARB-17, tlh, 16sRNA, tlh, tdh, and tox genes in $V$. parahaemolyticus, respectively, compared with the atpA gene (Fig. 4). The trh revealed the highest distance of 0.736 and the lowest distance involved with the $t d h$ gene was 0.000 , showing the low divergence and lowest specificity for detection of $t d h$ (Fig. 5).

The expression levels of the pirA gene, the virulence gene of AHPND-positive isolates, after incubation for $4 \mathrm{~h}$ at $37^{\circ} \mathrm{C}$ was determined. This result showed that the pirA gene was expressed in all AHPND-positive isolates, but that levels of expression were variable (Fig. 6).

\section{Discussion}

In this study, highly conserved detection gene 16S rRNA (Tarr et al. 2007), atpA (Izumiya et al. 2011), blaCARB-17 ( $\mathrm{Li}$ et al. 2016), virulence gene pirA (Sirikharin et al. 2014; Han

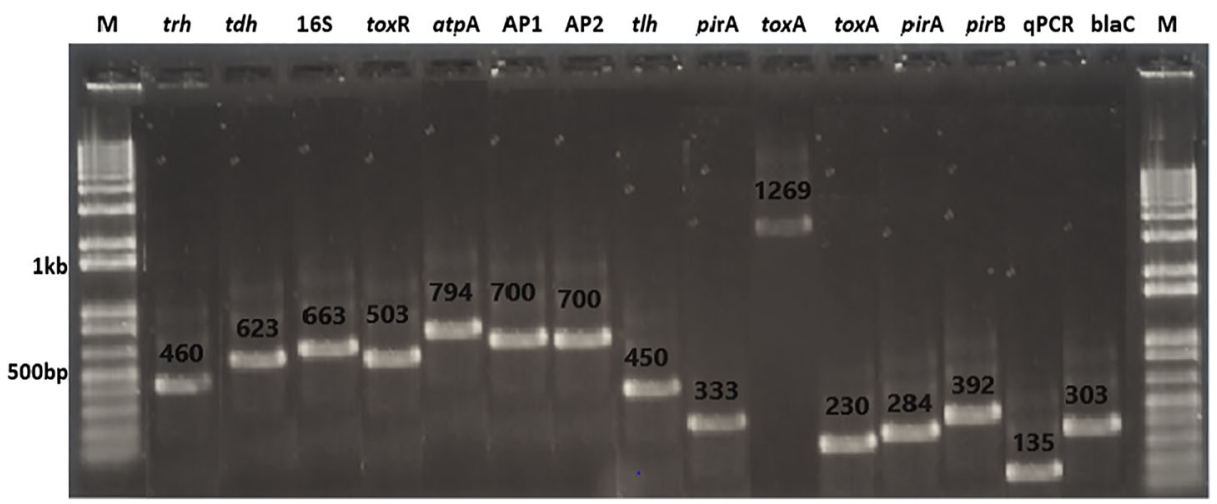

Fig. 1 The results of the PCR fingerprints, $t r h, t d h, 16 \mathrm{~S}$ rRNA, toxR, atpA, AP1, AP2, tlh, pirA (AP3), toxA, pirA, pir B, qPCR products, and blaCARB-17 amplification in AHPND-positive isolates. 1\% agarose gel shows the amplicons of target genes in this strain. Lane M: DNA marker; lane 2-16: positive amplicons of representative strain of Vibrio parahaemolyticus (ahpn-25) respectively. Molecular weight, in the first and last lane, corresponds to ladder $100 \mathrm{bp}$ 

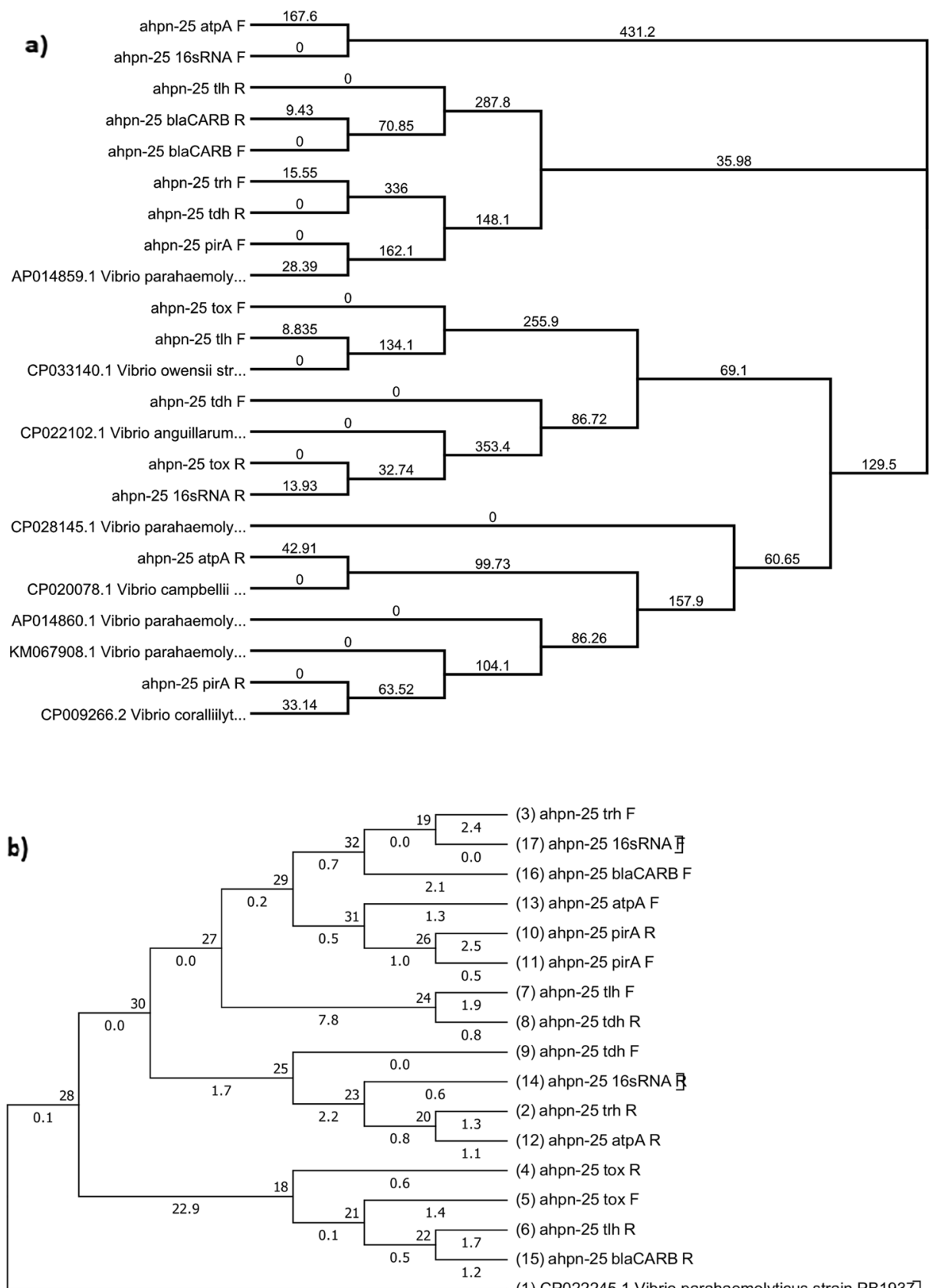

(3) ahpn-25 trh F

(17) ahpn-25 16sRNA

(16) ahpn-25 blaCARB F

(13) ahpn-25 atpA F

(10) ahpn-25 pirA R

(11) ahpn-25 pirA F

(7) ahpn-25 tlh F

(8) ahpn-25 tdh R

(9) ahpn-25 tdh F

(14) ahpn-25 16sRNA $\bar{B}$

(2) ahpn-25 trh R

(12) ahpn-25 atpA R

(4) ahpn-25 tox R

(5) ahpn-25 tox $F$

(6) ahpn-25 th R

(15) ahpn-25 blaCARB R

1.3

(1) CP022245.1 Vibrio parahaemolyticus strain PB1937]

Fig. 2 a Phylogenetic tree of AHPND-positive isolates and the reference strains. AHPND-positive isolates used in this study are named in ahpn-25 as a representative strain. The neighbor-joining tree shows the phylogenetic

et al. 2015b), trh (Suthienkul et al. 1995), tdh (Karunasagar et al. 1996), trh (Dickinson et al. 2013) and toxic genes toxR (Neogi et al. 2010) toxA (Dangtip et al. 2015), and pirB (Han et al. 


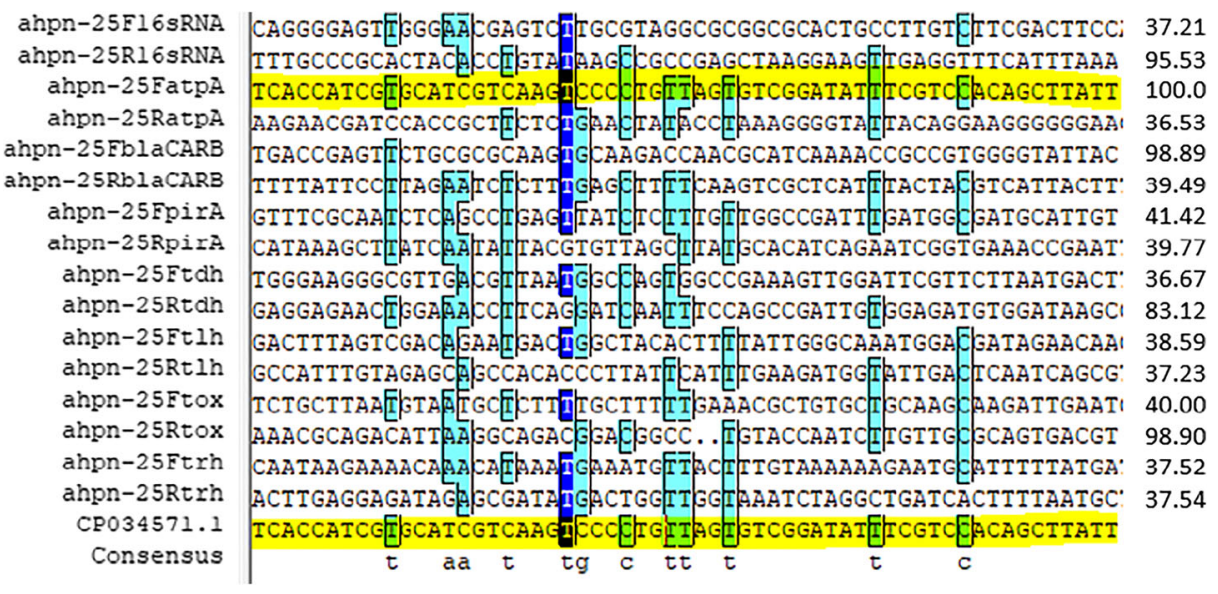

Fig. 3 Multiple sequence alignment and pairwise alignment score (right) of 16S rRNA, atpA, blaCARB-17, pirA (AP3), $t d h, t l h, t o x$, and trh partial gene sequences with the reference strain of Vibrio parahaemolyticus accession no. CP034571.1 using ClustalW and DNAMAN

2015b) were isolated from 23 AHPND-positive isolates. AHPND causes early mortality syndrome (De Schryver et al. 2014) and outbreaks (Chonsin et al. 2015) in the shrimp aquaculture industry of Bangladesh. As previously reported, AHPND is characterized by two pir genes (Lai et al. 2015) which are deadly (Lee et al. 2015), binary toxins pirA and pirB (Kondo et al. 2014; Han et al. 2015b) genes found in isolates of V. parahaemolyticus of P. monodon.

To construct the phylogenetic relationship (Li et al. 2016), 8 Vibrio spp. were selected from GeneBank to compare with target gene sequences; all genes were derived from a common ancestor. The derived traits of pirA, atpA, 16S rRNA, tox, and tdh genes had a common ancestor sharing $100 \%$ identity with the reference strain of $V$. parahaemolyticus (accession nos. CP028145.1, AP014860.1, and KM067908.1); trh, blaCARB-17, and th genes had a common ancestor sharing $100 \%$ identity with the reference strain of $V$. parahaemolyticus (accession no. AP014859.1) (Fig. 2a). All genes showed a common ancestor (accession no. CP022245.1), wherein all clades were derived with different traits with very low genetic distance (Fig. 2b). The phylogenetic relationship in the sequence of target genes showed that AHPND-positive isolates belonged to Vibrio spp. and all of which were close to $V$. parahaemolyticus. The variability (Liu et al. 2015) of the target genes (toxR, 16S rRNA, pirA (AP3), toxA, blaCARB-17, tlh, atpA, tdh, and trh) sequence was analyzed. The few mutations and sequence inaccuracy were identified in the starting and middle regions of the genes. The genetic variations (Chonsin et al. 2015) including missing nucleotide through gene sequencing were examined.

The sequences of the PCR amplification (Kondo et al. 2014; Restrepo et al. 2016) of target genes (toxR, 16S rRNA, pirA (AP3), toxA, blaCARB-17, th, atpA, tdh, and trh) from an AHPND-positive representative strain (ahpn-25) were aligned with the reference strain of V. parahaemolyticus (accession no. CP034571.1) with low variability (Fig. 3). The atpA gene in AHPND-positive isolates produced high homology and 100\% pairwise alignment with the reference strain in this research. The eight different target genes were aligned and obtained a consensus sequence. The pairwise alignment scores for atpA, tox, blaCARB-17, 16S rRNA, and pirA gene were 100.0, 98.90, 98.89, 95.53, and 41.42, respectively, in the AHPND- 


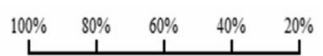

LK021128.1_Vibrio_anguillanum

CP021148.1_Vibrio_campbellii

ahpn-25_16sRNA.tst

CP033146.1_Vibrio_owensii

AP014860.1_Vibrio_parahaemolyticus
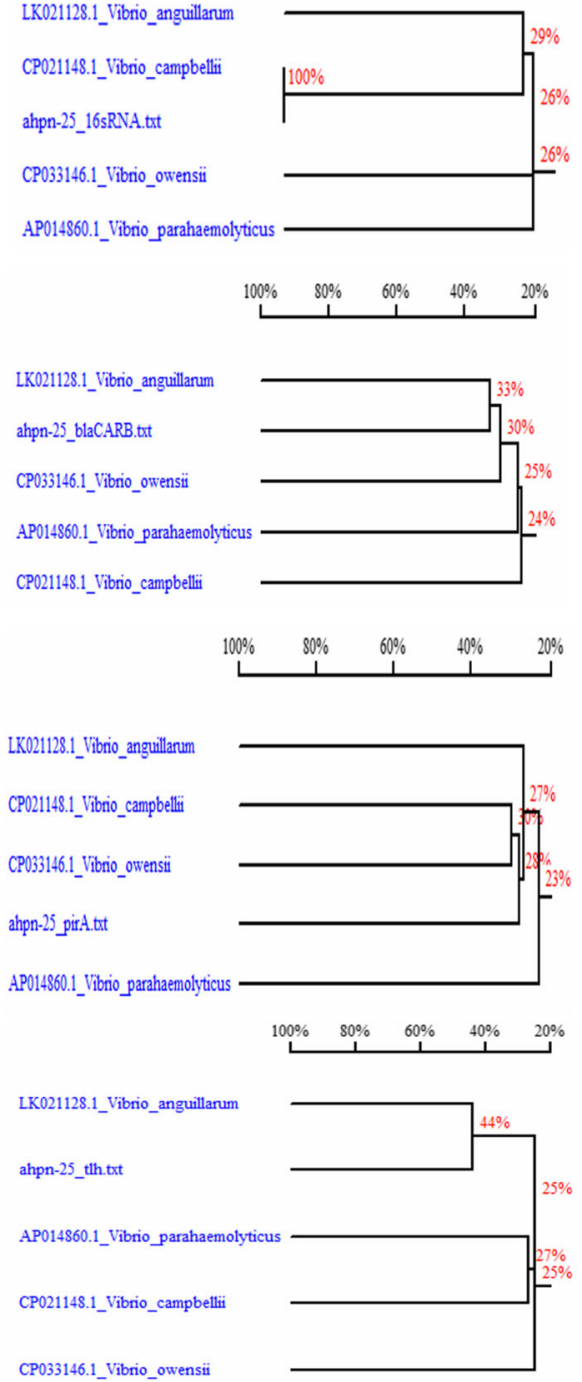

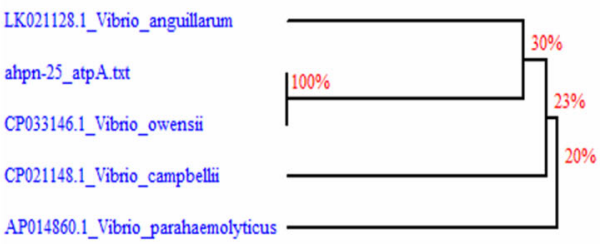

AP014860.1_Vibrio_parahaemolyticus
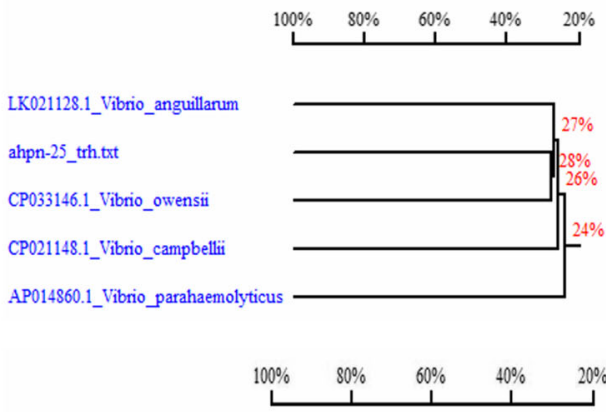

LK021128.1_Vibrio_anguillarum

AP014860.1_Vibrio_parahaemolyticus

ahpn-25_th.tat

CP021148.1_Vibrio_campbellii

CP033146.1_Vibrio_owensii
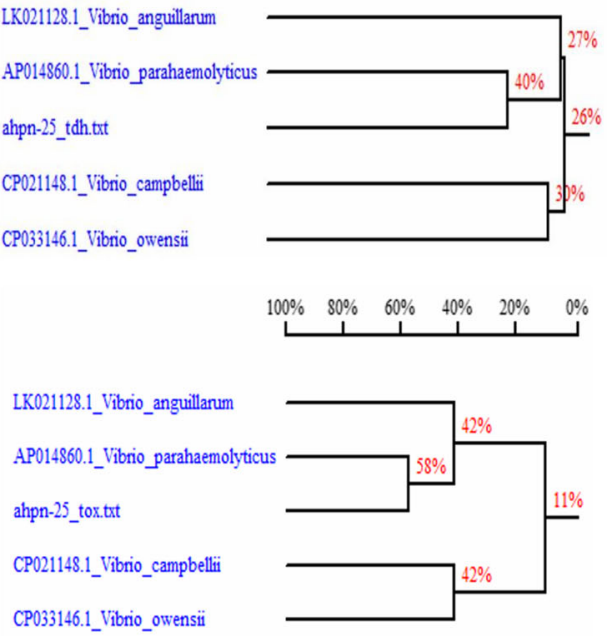

Fig. 4 Comparison of sequence homology; the sequence of AHPND-positive strain (ahpn-25) for eight genes used as Vibrio parahaemolyticus detection targets. The 16S rRNA, pirA (AP3), tox, blaCARB-17, tlh, atpA, $t d h$, and trh gene homology compared with Vibrio sp. (NCBI accession no. LK021128.1, AP014860.1, CP021148.1, and CP033146.1)

positive strain ahpn-25. Variations included a missing nucleotide position in the sequence of all target genes in this study analyzed by ORFfinder and RCSB PDB, by using Smart BLAST (CDD) and NCB (Marchler-Bauer et al. 2017; Marchler-Bauer et al. 2015; Marchler-Bauer et al. 2013). This result revealed some bacterial virulence proteins such as VirB8 and VirB10 (accession no: cl01500), TrbE (accession no: cl36305), sopB_N and ParB (accession nos: cd16394 and cl38291), TraF (accession no: c131246), Tra8 (accession no: COG2826), 


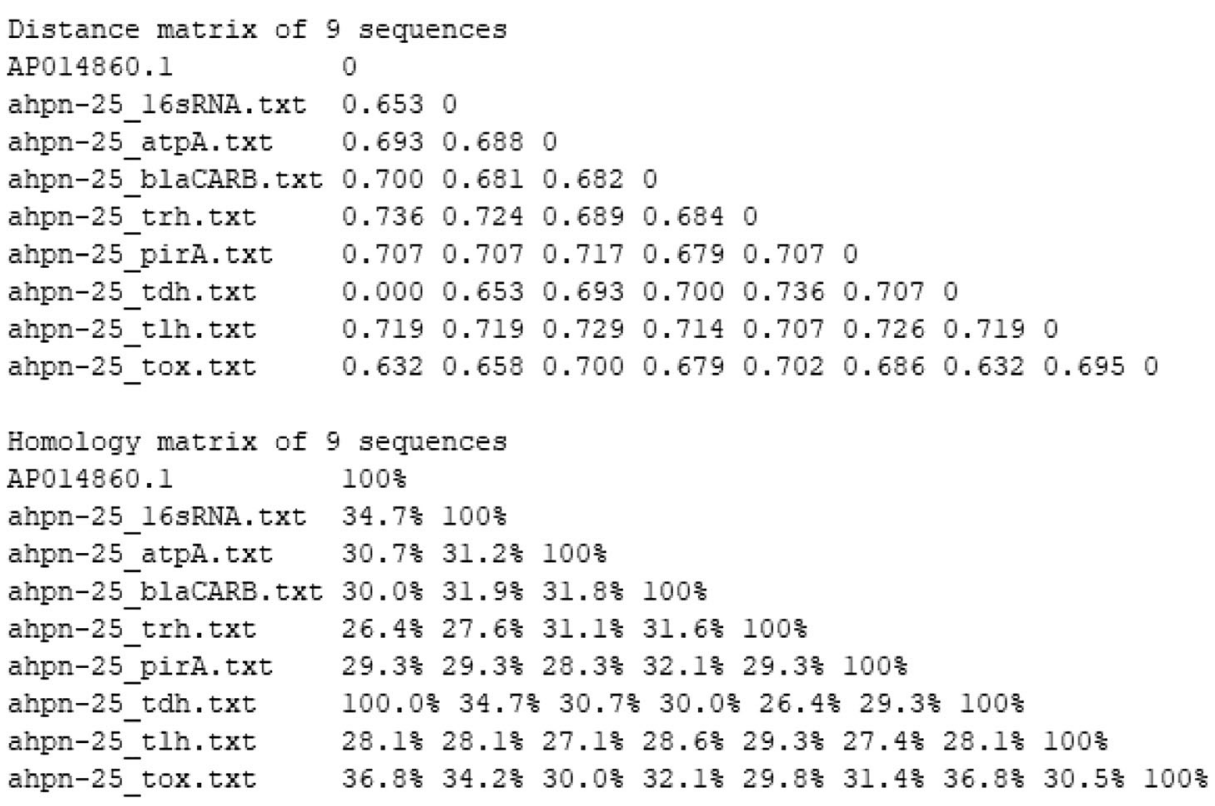

Fig. 5 Distance and homology matrix of AHPND-positive strain (ahpn-25) for eight genes used as Vibrio parahaemolyticus detection targets compared with $V$. parahaemolyticus (NCBI accession no. AP014860.1)

PRK00409 (accession no: cl29770), and SR_Res par (accession no: cd03767), which may conserved the protein domain family in the sequences of $16 \mathrm{~S}$ rRNA, blaCARB-17, pirA, $t d h$, tlh, tox, and trh gene.

The PCR amplification, agarose gel electrophoresis, and RT-qPCR assay of target genes 16S rRNA, blaCARB-17 and atpA revealed accurate amplified fragment in Fig. 1 and comparatively high expression and constantly maintained 100\% specificity in Table 2 for V. parahaemolyticus (Izumiya et al. 2011; Dickinson et al. 2013) in parallel with different isolates in Table 3. Accordingly, the PCR, electrophoresis, and RT-qPCR assay of target genes

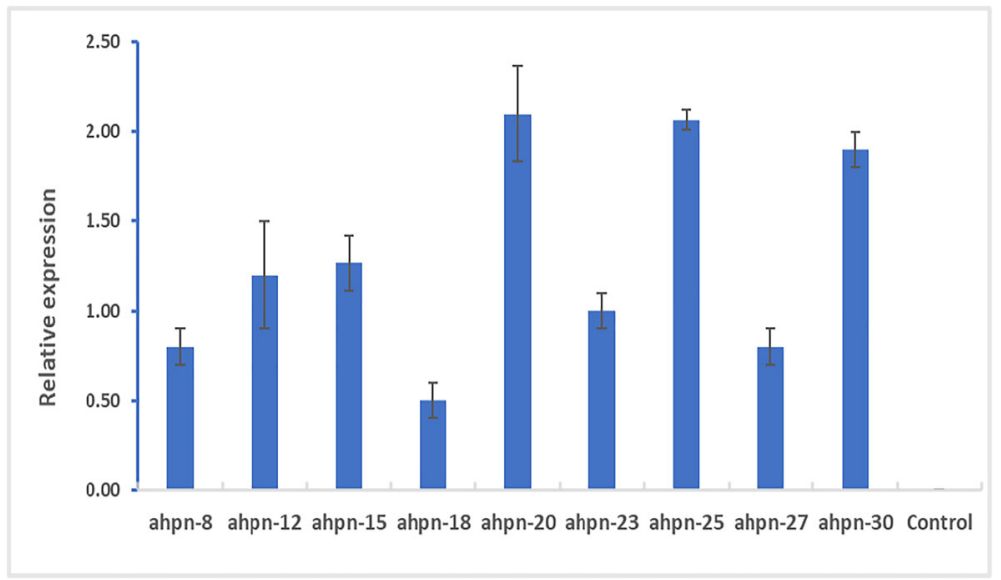

Fig. 6 Relative gene expression levels determined by RT-qPCR of pirA in AHPND-positive isolates incubated for $4 \mathrm{~h}$ at $37^{\circ} \mathrm{C}$ in tryptone soya broth (TSB) culture medium. A non-AHPND strain ATCC17802 was used as the negative control. Error bars indicate standard error 
toxR, pirA (AP3), toxA, tlh, tdh, and trh yielded less specificity and low expression. The level of specificity is unsatisfactory in rapid molecular methods for identifying $V$. parahaemolyticus, thereby hindering its comprehensive application in routine laboratory tests (Klein et al. 2014). This result assured that the isolates isolated from shrimp farms were all toxic to shrimp, but their virulence was different, and the relative expression level was variable between isolates. In this study, the relative expression levels determined by RT-qPCR (Karunasagar et al. 1996; Gutierrez West et al. 2013) of target genes showed that nine target genes were expressed in AHPND-positive representative strain, but that levels of expression were variable. The atpAlike gene exhibited the lowest degrees of similarity in $V$. parahaemolyticus and highest in $V$. anguillarum via homology analysis, indicating the most divergence in AHPND-positive isolates (Restrepo et al. 2016). The homology distance matrix for target genes of AHPNDpositive strain (ahpn-25) was compared with that of reference strain (accession no: AP014860.1).

The sensitivity and specificity of RT-qPCR applied in this work can be useful to detect $V$. parahaemolyticus in shrimp (Penaeus monodon) in epidemiological research. All target genes in $V$. parahaemolyticus that may be causal agents of AHPND in shrimp may require a suitable vaccine development to prevent AHPND in Bangladesh.

Acknowledgments We thank the members of the Biotechnology laboratory, Bangladesh Institute of Nuclear Agriculture (BINA), Bangladesh Agricultural University (BAU) and Genome Center, Central Laboratory and Fisheries and Marine Bioscience Laboratory, Microbiology Laboratory of Jashore University of Science and Technology (JUST) for their expert advice and editing. I sincerely appreciate and like to thank Dr. M. A. Swaraz, Associate Professor, Department of Engineering and Biotechnology of JUST for his suggestions in the bioinformatic analysis. We also thank the Ministry of Education (BANBEIS), Bangladesh, for financing this research, but the BANBEIS had no contributions with study design, sample collection, data analysis, decision to publish, and preparation of the manuscript.

Author contribution Dr. Md. Mer Mosharraf Hossain, Dr. Imtiaz Uddin, and Dr. Md. Anisur Rahman designed the study, and Habiba Islam, Jannatul Fardous, Md. Ariful Haque Rupom, Md. Monjur Hossain, Nawshin Farjana, Rukaiya Afroz, and Md. Asif Shahriar Shehab conducted the experiments, analyzed the data, and wrote the manuscript. Dr. Md. Mer Mosharraf Hossain was actively associated with experimental works and data processing. Hasan-Uj-Jaman and Hironmoy Shovon Roy was directly involved with shrimp farm and shrimp farmers to collect different kind of shrimp samples (healthy or diseased). The authors would like to thank everyone who was indirectly associated with this work. All authors read and approved the manuscript.Data availabilityThe data in this article had not been previously shared or published anywhere else. The datasets supporting the conclusions of this article are included with the article.

\section{Compliance with ethical standards}

Conflict of interest The authors declare that they have no conflicts of interest.

Ethical approval The ethical committee of the Department of Fisheries and Marine Bioscience, Jashore University of Science and Technology, Bangladesh, approved these experiments.

\section{References}

Austin B (2010) Vibrios as causal agents of zoonoses. Vet Microbiol 140:310-317

Chonsin K, Matsuda S, Theethakaew C, Kodama T, Junjhon J, Suzuki Y, Suthienkul O, Iida T (2015) Genetic diversity of Vibrio parahaemolyticus strains isolated from farmed Pacific white shrimp and ambient pond 
water affected by acute hepatopancreatic necrosis disease outbreak in Thailand. FEMS Microbiol Lett 363: $1-8$

Dangtip S, Sirikharin R, Sanguanrut P, Thitamadee S, Sritunyalucksana K, Taengchaiyaphum S, Mavichak R, Proespraiwong P, Flegel TW (2015) AP4 method for two-tube nested PCR detection of AHPND isolates of Vibrio parahaemolyticus. Aquacult Rep 2:158-162

De Schryver P, Defoirdt T, Sorgeloos P (2014) Early mortality syndrome outbreaks: a microbial management issue in shrimp farming. PLoS Pathog 10:e1003919

Dickinson G, Lim K, Ying, Jiang SC (2013) Quantitative microbial risk assessment of pathogenic vibrios in marine recreational waters of Southern California. Appl Environ Microbiol 79:294-302

Feng B, Liu H, Wang M, Sun X, Pan Y, Zhao Y (2017) Diversity analysis of acute hepatopancreatic necrosis disease-positive Vibrio parahaemolyticus strains. Aquac Fish 2:278-285

Flegel T (2014) A game changer for the future development of aquaculture. In: 9th symposium on diseases in Asian aquaculture, Ho Chi Minh City, Vietnam

Flegel T, Lo C (2013) Announcement regarding free release of primers for specific detection of bacterial isolates that cause acute hepatopancreatic necrosis disease (AHPND). Aquacult Asia 19:30

Flegel T, Lo C (2014a) Announcement regarding free release of primers for specific detection of bacterial isolates that cause acute hepatopancreatic necrosis disease (AHPND). Aquacult Asia 19:30

Flegel TW, Lo CF (2014b) Interim primers for specific detection of bacterial isolates that cause acute hepatopancreatic necrosis disease (AHPND). World Aquaculture Society, World Aquaculture Society Meetings, Meeting Abstract

Gutierrez West CK, Klein SL, Lovell, Harles R (2013) High frequency of virulence factor genes $t d h, t r h$, and $t l h$ in Vibrio parahaemolyticus strains isolated from a pristine estuary. Appl Environ Microbiol 79:2247-2252

Han JE, Tang KFJ, Lightner DV (2015a) Genotyping of virulence plasmid from Vibrio parahaemolyticus isolates causing acute hepatopancreatic necrosis disease in shrimp. Dis Aquat Org 115(3):245-251

Han JE, Tang KFJ, Pantoja CR, White BL, Lightner DV (2015b) QPCR assay for detecting and quantifying a virulence plasmid in acute hepatopancreatic necrosis disease (AHPND) due to pathogenic Vibrio parahaemolyticus. Aquaculture 442:12-15

Ishimaru K, Akagawa-Matsushita M, Muroga K (2009) Vibrio penaeicida sp. nov., a pathogen of kuruma prawns (Penaeus japonicus). Int J Syst Bacteriol 45:134-138

Izumiya H, Matsumoto K, Yahiro S, Lee J, Morita M, Yamamoto S, Arakawa E, Ohnishi M (2011) Multiplex PCR assay for identification of three major pathogenic Vibrio spp., Vibrio cholerae, Vibrio parahaemolyticus, and Vibrio vulnificus. Mol Cell Probes 25:174-176

Kannapiran E, Ravindran J, Chandra R, Kalaiarasi A (2009) Studies on luminous, Vibrio harveyi associated with shrimp culture system rearing Penaeus monodon. J Environ Biol 30:791-795

Karunasagar I, Sugumar G, Karunasagar I, Reilly PJA (1996) Rapid polymerase chain reaction method for detection of Kanagawa positive Vibrio parahaemolyticus in seafoods. Int J Food Microbiol 31:317-323

Kaysner CA, DePaola AJ (2004) Vibrio cholerae, V. parahaemolyticus, V. vulnificus and other Vibrio spp. In FDA 136 Journal of Animal Research: v.8 n.1, February 2018 Patel et al. Bacteriological Analytical Manual, 8th ed. revised. AOAC International, Gaithersburg, MD., 9:9.01-9.27

Kim YB, Okuda J, Matsumoto C, Takahashi N, Hashimoto S, Nishibuchi M (1999) Identification of Vibrio parahaemolyticus strains at the species level by PCR targeted to the toxR gene. J Clin Microbiol 37:11731177

Kim HJ, Ryu JO, Lee SY, Kim ES, Kim HY (2015) Multiplex PCR for detection of the Vibrio genus and five pathogenic Vibrio species with primer sets designed using comparative genomics. BMC Microbiol 15:1-11

Klein SL, Gutierrez West CK, Mejia DM, Lovell CR (2014) Genes similar to the Vibrio parahaemolyticus virulence-related genes $t d h$, $t l h$, and vscC2 occur in other vibrionaceae species isolated from a pristine estuary. Appl Environ Microbiol 80:595-602

Kondo H, Tinwongger S, Proespraiwong P, Mavichak R, Unajak S, Nozaki R, Hiron I (2014) Draft genome sequences of six strains of Vibrio parahaemolyticus isolated from early mortality syndrome/acute hepatopancreatic necrosis disease shrimp in Thailand. Genome Announc 2:2-3

Kumar S, Stecher G, Li M, Knyaz C, Tamura K (2018) MEGA X: molecular evolutionary genetics analysis across computing platforms. Mol Biol Evol 35:1547-1549

Lai HC, Ng TH, Ando M, Te C, Lee IT, Chen JCC, Mavichak R, Chang SH, De M, Yeh YA, Chiang H, Takeyama HO, Hamaguchi CF, Lo TA, Wang HC (2015) Pathogenesis of acute hepatopancreatic necrosis disease (AHPND) in shrimp. Fish Shellfish Immunol 47:1006-1014

Lee CT, Chen IT, Yang YT, Ko TP, Huang YT, Huang JY, Huang MF, Lin SJ, Chen CY, Lin SS, Lightner DV, Wang H-C, Wang AHJ, Wang H-C, Hor LI, Lo CF (2015) The opportunistic marine pathogen Vibrio parahaemolyticus becomes virulent by acquiring a plasmid that expresses a deadly toxin. Proc Natl Acad Sci 112:10798-10803 
Li R, Chiou J, Chan EWC, Chen S (2016) A novel PCR-based approach for accurate identification of Vibrio parahaemolyticus. Front Microbiol 7:1-5

Li P, Kinch LN, Ray A, Dalia AB, Cong Q, Nunan LM, Camilli A, Grishin NV, Salomon D, Orth K (2017) Acute hepatopancreatic necrosis strains maintain an antibacterial type vi secretion system with versatile effector. Appl Environ Microbiol 83:1-17

Liu L, Xiao J, Xia X, Pan Y, Yan S, Wang Y (2015) Draft genome sequence of Vibrio owensii strain SH-14, which causes shrimp acute hepatopancreatic necrosis disease. Genome Announc 3:e01395-e01315

Marchler-Bauer A, Zheng C, Chitsaz F, Derbyshire MK, Geer LY, Geer RC, Gonzales NR, Gwadz M, Hurwitz DI, Lanczycki CJ, Lu F, Lu S, Marchler GH, Song JS, Thanki N, Yamashita RA, Zhang D, Bryant SH (2013) CDD: conserved domains and protein three-dimensional structure. Nucleic Acids Res 41:D348D352

Marchler-Bauer A, Derbyshire MK, Gonzales NR, Lu S, Chitsaz F, Geer LY, Geer RC, He J, Gwadz M, Hurwitz DI, Lanczycki CJ, Lu F, Marchler GH, Song JS, Thanki N, Wang Z, Yamashita RA, Zhang D, Zheng C, Bryant SH (2015) CDD: NCBI's conserved domain database. Nucleic Acids Res 43:D222-D226

Marchler-Bauer A, Bo Y, Han L, He J, Lanczycki CJ, Lu S, Chitsaz F, Derbyshire MK, Geer RC, Gonzales NR, Gwadz M, Hurwitz DI, Lu F, Marchler GH, Song JS, Thanki N, Wang Z, Yamashita RA, Zhang D, Zheng C, Geer LY, Bryant SH (2017) CDD/SPARCLE: functional classification of proteins via subfamily domain architectures. Nucleic Acids Res 45:D200-D203

Mohney LL, Lightner DV, Bell TA (1994) An epizootic of vibriosis in Ecuadorian pond-reared Penaeus vannamei Boone (Crustacea: Decapoda). J World Aquac Soc 25:116-125

Neogi SB, Chowdhury N, Asakura M, Hinenoya A, Haldar S, Saidi SM, Kogure K, Lara RJ, Yamasaki S (2010) A highly sensitive and specific multiplex PCR assay for simultaneous detection of Vibrio cholerae, Vibrio parahaemolyticus and Vibrio vulnificus. Lett Appl Microbiol 51(3):293-300

Praveena PE, Bhuvaneswari TSK, Otta RN, J. KP (2014) Histopathology and its importance in shrimp disease diagnosis. Training manual on health management practices for finfish and shellfish of brackishwater environment. Train Manual Aqua Ani Heal Environ Div 74:91-97

Restrepo L, Bayot B, Betancourt I, Pinzón A (2016) Draft genome sequence of pathogenic bacteria Vibrio parahaemolyticus strain Ba94C2, associated with acute hepatopancreatic necrosis disease isolate from South America. Genomics Data 9:143-144

Saitou N, Nei M (1987) The neighbor-joining method: a new method for reconstructing phylogenetic trees. Mol Biol Evol 4:406-425

Santos HM, Tsai CY, Maquiling KRA, Tayo LL, Mariatulqabtiah AR, Lee CW, Chuang KP (2020) Diagnosis and potential treatments for acute hepatopancreatic necrosis disease (AHPND): a review. Aquac Int 28(1): 169-185

Shinn AP, Jiravanichpaisal J, Grifffiths D, Pokharatsiri A, Burana P, Sumon T, Tongmee C, Decamp O, Galli L (2018a) Effect of biofloc on the survival of whiteleg shrimp, Penaeus vannamei Boone 1931, when challenged with a pathogenic strain of Vibrio parahaemolyticus, the causative agent of acute hepatopancreatic necrosis disease. Asian Fish Sci 31S:210-225

Shinn AP, Pratoomyot J, Griffiths D, Trong TQ, Vu NT (2018b) Asian shrimp production and the economic costs of disease. Asian Fish Sci 31S:29-58

Sirikharin R, Taengchaiyaphum S, Sritunyalucksana K, Thitamadee S, Flegel TW, Mavichak R (2014) A new and improved PCR method for detection of AHPND bacteria. Netw Aquac Centres Asia-Pacific:7-9

Sirikharin R, Taengchaiyaphum S, Sanguanrut P, Chi TD, Mavichak R, Proespraiwong P, Nuangsaeng B, Thitamadee S, Flegel TW, Sritunyalucksana K (2015) Characterization and PCR detection of binary, pir-like toxins from Vibrio parahaemolyticus isolates that cause acute hepatopancreatic necrosis disease (AHPND) in shrimp. PLoS One 10:1-16

Soto-Rodriguez SA, Gomez-Gil B, Lozano-Olvera R, Betancourt-Lozano M, Morales-Covarrubias MS (2015) Field and experimental evidence of Vibrio parahaemolyticus as the causative agent of acute hepatopancreatic necrosis disease of cultured shrimp (Litopenaeus vannamei) in northwestern Mexico. Appl Environ Microbiol 81(5):1689-1699

Suthienkul O, Ishibashi M, Iida T (1995) Urease production correlates with possession of the trh gene in vibrio parahaemolyticus strains isolated in Thailand. J Infect Dis 172:1405-1408

Tamura K, Nei M, Kumar S (2004) Prospects for inferring very large phylogenies by using the neighbor-joining method. Proc Natl Acad Sci 101:11030-11035

Tarr CL, Patel JS, Puhr ND, Sowers EG, Bopp CA, Strockbine NA (2007) Identification of Vibrio isolates by a multiplex PCR assay and rpoB sequence determination. J Clin Microbiol 45:134-140

Tinwongger S, Proespraiwong P, Thawonsuwan J, Sriwanayos P, Kongkumnerd J, Chaweepack T, Mavichak R, Unajak S, Nozaki R, Kondo H, Hirono I (2014) Development of PCR diagnosis for shrimp acute hepatopancreatic necrosis disease (AHPND) strain of Vibrio parahaemolyticus. Fish Pathol 49:159-164 
Zhang L, Orth K (2013) Virulence determinants for Vibrio parahaemolyticus infection. Curr Opin Microbiol 16: $70-77$

Zorriehzahra M, Banaederakhshan R (2013) Early mortality syndrome (EMS) as new emerging threat in shrimp industry. Adv Anim Vet Sci 3:51-65

Publisher's note Springer Nature remains neutral with regard to jurisdictional claims in published maps and institutional affiliations.

\section{Affiliations}

Md. Mer Mosharraf Hossain ${ }^{1} \cdot$ Md. Imtiaz Uddin ${ }^{2} \cdot$ Habiba Islam ${ }^{1} \cdot$ Jannatul Fardoush $^{1}$ • Md. Ariful Haque Rupom ${ }^{1} \cdot$ Md. Monjur Hossain ${ }^{2} \cdot$ Nawshin Farjana $^{1}$ • Rukaiya Afroz ${ }^{1} \cdot$ Hasan-Uj-Jaman ${ }^{3} \cdot$ Hironmoy Shovon Roy ${ }^{4} \cdot$ Md. Asif Shahriar Shehab ${ }^{1} \cdot$ Md. Anisur Rahman ${ }^{1}$

Md. Mer Mosharraf Hossain mmm.hossain@just.edu.bd

Jashore University of Science and Technology, Jashore, Bangladesh

2 Bangladesh Institute of Nuclear Agriculture, Mymensingh, Bangladesh

3 PCF Feed Industries Ltd, Khulna, Bangladesh

4 CP Bangladesh Ltd, Dhaka, Bangladesh 